\title{
Plano de gerenciamento de resíduos sólidos para uma indústria de cerâmica vermelha
}

A produção desenfreada e diversificada dos resíduos sólidos tornou-se nas últimas décadas um grave e complexo problema ambiental, em virtude do mau gerenciamento que atualmente vem sendo empregado a esses resíduos. Em vista a essa problematização, este trabalho teve como objetivo propor um Plano de Gerenciamento dos Resíduos Sólidos - PGRS para uma indústria de cerâmica vermelha, localizada na microrregião do Cariri cearense. No desenvolvimento dessa pesquisa considerou-se uma abordagem quali-quantitativa e exploratória para avaliação dos dados que subsidiaram esse estudo. Inicialmente foi realizada uma revisão na literatura vigente sobre o assunto inerente a pesquisa, bem como os aspectos contidos em normas e leis referentes à preservação ambiental. Após a avaliação, constatou-se a inexistência de um plano de gerenciamento de resíduos sólidos na fábrica e que a mesma realiza a destinação inadequada desses materiais. Nota-se que a principal fonte geradora de resíduos nessa indústria são as perdas de blocos oriundas na etapa pós-queima (cerca de $168.000 \mathrm{~kg} / \mathrm{mensais}$ no período de estiagem) e também o excesso de cinzas (1200 kg/mensais). Por fim, foi efetuada a elaboração da proposta do plano de gerenciamento dos resíduos sólidos para a referida indústria.

Palavras-chave: Cerâmica vermelha; Resíduos sólidos; Gerenciamento.

\section{Solid waste management plan for a red ceramic industry}

\begin{abstract}
The production unbridled and diversified of solid waste has become in the last decades a severe and complex environmental problem, in virtue of bad management what currently comes being employee these wastes. In view the that problematization, this work has as goal propose a Solid Waste Management Plan - PGRS for an industry of red ceramics, localized at microregion of Cariri at the Ceará. At the development of that search it was considered an approach qualitative-quantitative and exploratory for evaluation of data what subsidized this study. Initially it was realized a review at literature actual about the subject matter inherent the search, as well as the aspects contained in norm and laws referring environmental preservation. After the evaluation, verified the inexistence of a solid waste management plan at industry and what a same realizes the destination inadequate of these materials. It is noted that the main source generating of waste in this industry are the losses of blocks originating at stage post-burn (about $168,000 \mathrm{~kg} / \mathrm{month}$ in the dry season) and also the excess of ashes (1200 kg/month). Lastly, it was realized the elaboration of the proposal of solid waste management plan for the referred to industry.
\end{abstract}

Keywords: Red Ceramics; Solid waste; Management.

Topic: Engenharia Ambiental

Reviewed anonymously in the process of blind peer.
Received: $12 / 08 / 2019$

Approved: 22/11/2019
Erlan Freires de Oliveira

Instituto Federal do Ceará, Brasil

http://lattes.cnpq.br/3916444946746814

erlanmajo@gmail.com

Ismael Keslley Carloto Lopes

Instituto Federal do Ceará, Brasil

http://lattes.cnpq.br/6221548663584268

ismaellopes618@gmail.com

Esdras Alex Freire de Oliveira

Universidade Regional do Cariri, Brasil

http://lattes.cnpq.br/4693470747465264

esdras-alex@hotmail.com
Alex Jussileno Viana Bezerra

Instituto Federal do Ceará, Brasil

http://lattes.cnpq.br/2032999287479186

alexleno@ifce.edu.br
Referencing this:

OLIVEIRA, E. F.; LOPES, I. K. C.; OLIVEIRA, E. A. F.; BEZERRA, A. J. V.. Plano de gerenciamento de resíduos sólidos para uma indústria de cerâmica vermelha. Engineering Sciences, v.7, n.3, p.73-83, 2019. DOI: http://doi.org/10.6008/CBPC2318-3055.2019.003.0007 


\section{INTRODUÇÃO}

O gerenciamento inapropriado dos resíduos sólidos é considerado um dos principais problemas que assolam o meio ambiente, em razão da grande quantidade e diversidade de insumos que são gerados constantemente por entidades públicas, privadas e locais residenciais. Segundo Moura (2016) o gerenciamento dos resíduos sólidos realizado de forma incorreta provoca inúmeros problemas socioambientais, tais como: a poluição do solo via alteração pedológica das características físico-químicas, contaminação das águas subterrâneas através da percolação do líquido e a poluição do ar.

No meio industrial a má gestão dos resíduos sólidos se tornou ainda mais preocupante, devido esses insumos serem diversificados e produzidos em grandes quantidades, sendo que muitos destes podem apresentar características de resíduos perigosos. Segundo Mendonça (2015) os efeitos negativos da ação humana sobre o meio ambiente variam conforme a velocidade em que os recursos naturais são extraídos, o montante destes que é retirado no decorrer do tempo e as formas de tratamento que são empregada a esses resíduos.

Conforme Carleti (2013) o setor da indústria de cerâmica tem atingido baixos níveis de qualidade ambiental, sendo que no Nordeste essa atividade está associada ao problema de agravamento ambiental por poluir o meio ambiente e os ecossistemas regionais, caracterizando como externalidades negativas degradantes.

De acordo a Agência Brasileira de Desenvolvimento Industrial - ABDI (2010) o setor cerâmico atua no tratamento térmico de materiais não metálicos a altas temperaturas, sendo amplo e heterogêneo subdividido em vários outros segmentos, em razão de fatores relacionados às matérias-primas, propriedades e áreas de utilização. Essa agência destaca que um dos segmentos desse setor é o de cerâmica vermelha, que emprega no processo de trabalho materiais com coloração avermelhada que são utilizados na construção civil em produtos como: tijolos; blocos; telhas; elementos vazados; lajes; tubos cerâmicos e também em produtos de adorno e uso domésticos.

Devido ao agravamento dos problemas ambientais ocasionados pela gestão ineficiente dos resíduos sólidos nas últimas décadas, o Congresso Nacional sancionou em agosto de 2010 a Política Nacional dos Resíduos Sólidos - PNRS (Lei 12.305/2010). Essa lei Brasil (2010), reúne um conjunto de diretrizes e ações que tem como finalidade promover o gerenciamento adequado dos resíduos, bem como viabilizar uma gestão integrada e compartilhada dos resíduos. Conforme a PNRS os resíduos sólidos são definidos da seguinte forma:

[...] material, substância, objeto ou bem descartado resultante de atividades humanas em sociedade, a cuja destinação final se procede, se propõe proceder ou se está obrigado a proceder, nos estados sólido ou semissólido, bem como gases contidos em recipientes e líquidos cujas particularidades tornem inviável o seu lançamento na rede pública de esgotos ou em corpos d'água, ou exijam para isso soluções técnica ou economicamente inviáveis em face da melhor tecnologia disponível. (BRASIL, 2010)

De acordo com a Associação Brasileira de Normas Técnicas - ABNT (2004), os resíduos sólidos são materiais oriundos de atividades: industrial; domestica; hospitalar; comercial; agrícola; de serviços e de varrição, que podem encontra-se tanto no estado sólido como no estado semissólido. Ainda segundo essa 
norma, esses materiais são classificados conforme as suas características em duas classes distintas: perigosos (Classe I) e não perigosos (Classe II). Sendo que os nãos perigosos são divididos em mais duas categorias: não inertes (Classe II-A) e inertes (Classe II-B). Os resíduos não inertes apresentam propriedades como: biodegradabilidade, combustibilidade ou solubilidade em água. Já os inertes não possuem solubilidade quando em contato com água destilada ou deionizada. Os materiais perigosos apresentam características físico-químicas próprias definidas a seguir como: inflamabilidade; corrosividade; reatividade; toxicidade e patogenicidade.

O gerenciamento dos resíduos sólidos, segundo a PNRS (BRASIL, 2010), refere-se ao conjunto de ações realizadas direta/indiretamente nas etapas de coleta, transporte, transbordo, tratamento e destinação e/ou disposição final ambientalmente adequada dos resíduos, em acordo com o plano municipal de gestão integrada ou com o plano de gerenciamento de resíduos. Dentre os instrumentos da PNRS, está o Plano de Gerenciamento de Resíduos Sólidos - PGRS, que é obrigatório para os seguintes estabelecimentos: os gerados nos serviços públicos de saneamento básico, os resíduos industriais, os de serviço de saúde e os resíduos oriundos da mineração.

A Resolução do Conselho Nacional de Meio Ambiente - CONAMA № 307/2002 (BRASIL, 2002) no seu art. $2 \circ$ inciso $\mathrm{V}$, indica que o gerenciamento dos resíduos sólidos tem por objetivo reduzir, reutilizar ou reciclar esses materiais, incluindo planejamento, responsabilidades, práticas, procedimentos e recursos para desenvolver e implementar as ações necessárias ao cumprimento das etapas previstas em programas e plano.

Diante da capacidade de mitigação dos danos ambientais ocasionado pelo tratamento inapropriado dos resíduos sólidos em indústrias de cerâmicas vermelha, o PGRS se torna um meio indispensável na gestão eficiente desses materiais. Para Morais (2015) a aplicação do PGRS em indústrias é de grande importância, pois além de reduzir os impactos ambientais advindos do mau gerenciamento dos resíduos, também atenuam os riscos à saúde do trabalhador e das comunidades próximas.

Nesse contexto, a presente pesquisa tem como objetivo elaborar propor Plano de Gerenciamento de Resíduos Sólidos - PGRS para uma indústria de cerâmica vermelha de pequeno porte localizada na microrregião do Cariri, no extremo sul do Estado do Ceará. Durante o desenvolvimento desse estudo buscouse avaliar, quantificar e classificar os resíduos gerados pela indústria de cerâmica, verificando os meios de destinação e disposição final utilizado pelo empreendimento, e assim, estabelecer subsídios que possa de certa forma aperfeiçoar a gestão desses materiais e promover um gerenciamento apropriado dos resíduos para esse tipo de atividade industrial. Desta forma a referida empresa poderá funcionar de maneira correta, sem ocasionar danos significativos para o ambiente, atuando em prol do desenvolvimento sustentável.

\section{METODOLOGIA}

A pesquisa desenvolvida nesse estudo é de abordagem quali-quantitativa e exploratório. Em princípio se constitui de um levantamento bibliográfico na literatura vigente, com o objetivo de familiarizar com os aspectos referentes ao gerenciamento dos resíduos sólidos presentes em leis, normas e estudos 
relacionados ao tema abordado. As classificações dos resíduos sólidos produzidos na fábrica foram realizadas conforme os aspectos contidos em normas como NBR 10004/2004 e a lei 12.305/2010 que trata da PNRS.

Para realização da etapa de apuração dos dados foram realizadas diversas visitas no local do empreendimento, onde foram utilizadas técnicas de observação direta, aplicação de questionários informais e entrevistas semiestruturadas com o representante da empresa, e posteriormente, realizado a caracterização e quantificação dos resíduos conforme a sua natureza e com o seu grau de periculosidade. Para quantificar os blocos cerâmicos que são perdidos durante processo produtivo foi utilizado como base o faturamento mensal do empreendimento (em média de 700 milheiros) e a capacidade que está sendo operada nos fornos (2000 blocos/linha). Através da avaliação desses parâmetros foi possível realizar uma estimativa do total de produtos defeituosos originados antes e depois do processo de queima.

Após a quantificação do total de milheiros perdidos no processo, foi utilizado uma balança de precisão para calcular a média do peso unitário dos blocos cerâmicos, onde foram escolhidos 10 blocos de forma aleatória da produção e aferido uma média 2,4 kg/bloco. A quantidade de cinzas geradas pelos fornos foi especificada pelo gerente do empreendimento, no qual o mesmo estabeleceu empiricamente um total de $1200 \mathrm{~kg} / \mathrm{mês}$ de cinzas.

Durante uma semana foi separado e pesado diariamente o resíduo orgânico que estava sendo produzido pelo empreendimento, com o intuito de estimar a média diária da geração desse tipo de insumo. Os demais resíduos foram quantificados de acordo com a quantidade que era comprada e destinada a coleta municipal.

Para alcance dos objetivos proposto, o estudo foi dividido em duas etapas, sendo que a primeira é composta pela descrição do empreendimento quanto a sua estrutura física. Na segunda etapa foi realizada a avaliação dos dados que subsidiaram este estudo para assim definir o adequado gerenciamento dos resíduos sólidos gerados.

\section{RESULTADOS E DISCUSSÃO}

\section{Caracterização do empreendimento}

A principal matéria-prima utilizada no processo de trabalho da indústria de cerâmicas vermelhas é a argila. Segundo Maia (2012), a argila vermelha é considerada um material heterogêneo que possui grande plasticidade quando em contato com a água, podendo ser queimado a temperaturas de até 1100 graus centígrados, adquirindo durante esse estágio colorações variando do creme a tons avermelhados, sendo que essa coloração está relacionado a quantidade de óxido de ferro presente na composição da argila.

De acordo com o projeto o terreno da empresa possui uma área total de $12.600 \mathrm{~m}^{2}$, sendo que a área construída corresponde a $8.309 \mathrm{~m}^{2}$. O empreendimento é composto por um galpão para secagem das peças pré-fabricadas; uma sala de escritório; um local para depósito de argila; um pátio para armazenamento de lenha; uma sala de máquinas e dois fornos, sendo que o primeiro é tipo contínuo (túnel) e o segundo do tipo abóbada. Os fornos contínuos são equipamentos térmicos em que o ciclo de queima é realizado sem 
interrupção, isto é, enquanto a queima dos blocos cerâmicos de uma vagoneta (carro transportador) chega ao final, outra está sendo iniciada, sem descontinuidade (MORAIS, 2007).

É utilizado material celulósico (lenha nativa e poda de cajueiro) como combustível para realização das atividades desempenhadas nos fornos. Essa indústria produz apenas um tipo de peça cerâmica (bloco de oito furos) destinado ao setor da construção civil. Durante as visitas ao local industrial, constatou-se a presença de outras empresas de mesmo segmento industrial na vizinhança, bem como casas multifamiliares e propriedades rurais.

O processo produtivo se inicia com a extração do minério (argila), sendo que essa extração é executada em terreno próximo a 4 km da indústria em questão. Esse processo de extração mineral pode ser realizado de forma manual (com pás) ou mecanizado (retroescavadeiras) dependendo do porte do empreendimento.

A fase de preparação da argila é desempenhada de forma semi-mecanizada com a utilização de máquina apropriada (desintegrador, também conhecida como destorroador de argila) para efetuar a homogeneização da matéria-prima, corrigindo a sua granulometria e eliminando eventuais substâncias indesejáveis no processo, em seguida adiciona-se água e outros aditivos ao mineral durante o processo de desintegração.

Após a argila atingir a plasticidade desejada, segue por esteira para a máquina extrusora (também conhecida por maromba), onde sofre o tratamento a vácuo para retirada do ar do material e em seguida é executada a etapa de modelagem por pressão, em que a argila processada passa pelo bocal desejado. Logo após efetuar-se o corte, o produto (bloco cru umidificado) é passado por um processo de inspeção para verificar a existência de imperfeições. Caso os mesmos estejam em boa qualidade, encaminha-se para etapa seguinte, caso contrário, retorna-se para o processo de extrusão.

Após a etapa anterior, os blocos são transportados em carros de mãos para o local onde é realizada a secagem do produto semiacabado e em sequência são empilhados adequadamente de forma a possibilitar uma boa circulação de ar entre eles. O processo de secagem adotado pelo empreendimento é realizado no meio natural em um galpão coberto (por telhas de amianto) com total ausência de radiação solar, sendo que o produto passa vários dias, a depender da época do ano, até atingir o ponto ideal antes de prosseguir para as etapas posteriores. Esse processo de secagem é efetuado progressivamente com o aproveitamento das condições climáticas (radiação térmica e ventos), no qual é de grande importância para garantir a qualidade do produto final, pois evita imperfeições nas peças nas fases seguintes, como rachaduras e trincas.

Logo após a etapa de secagem é realizada a seleção das peças não defeituosas que serão transportadas até o forno. As que apresentarem defeitos retornaram para o processo de desintegração ou destorroamento para serem novamente processadas. O empreendimento possui dois fornos um do tipo abóboda e outro contínuo, porém somente o do tipo contínuo está operando. Esse forno possui formato de túnel dividido por 60 linhas de capacidade de 2 milheiros, tendo uma capacidade total de produção de até 120 milheiros de blocos cerâmicos por ciclo de operação. O transporte das peças para a parte interna do forno é realizado com auxílio de carros de mãos devidamente adaptados, onde são organizados de tal forma 
que toda a radiação térmica liberada pela combustão da lenha (em torno de 800 graus centígrados) seja aproveitada ao máximo, sendo que o tempo de calcinação dos blocos é proporcional à quantidade depositada no interior dos túneis.

Após o processo de queima, o produto permanece no local até que a temperatura seja gradativamente diminuída em um período de aproximadamente 24 horas. Por fim, o produto é novamente inspecionado e selecionado de acordo com a qualidade física exigida do produto acabado, sendo armazenados no pátio da empresa estando pronto para ser comercializado. As peças que estiverem com algum defeito ou forem quebradas acidentalmente nesta etapa de carregamento do forno para a seção de estoque são descartadas e acumuladas em pilhas de entulho próximo ao pátio da cerâmica. 0 processo descrito anteriormente pode ser verificando na figura abaixo.

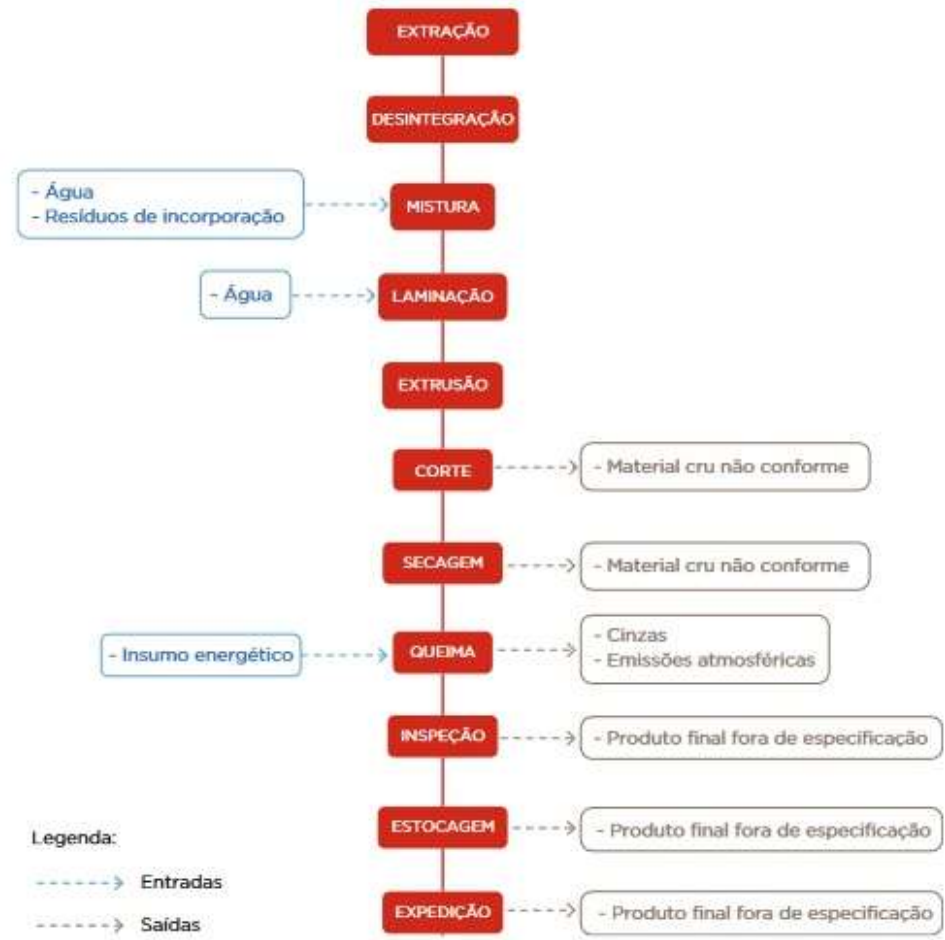

Figura 1: Fluxograma do processo produtivo. Fonte: Fiemg et al. (2013).

\section{Avaliação e identificação dos resíduos sólidos gerados}

A empresa trabalha somente na produção de blocos cerâmicos em formato retangular com oito furos, nas seguintes dimensões: $9.0 \mathrm{~cm}$ de largura, por $19.0 \mathrm{~cm}$ de comprimento e $19.0 \mathrm{~cm}$ de altura. Foi calculada a média para o peso da peça cerâmica que resultou em $2.4 \mathrm{~kg} /$ bloco. A produção média da empresa é de aproximadamente 700 mil blocos mensais, podendo ocorrer alterações na produção durante as épocas do ano. O período chuvoso da região é entre os meses de fevereiro a maio, com precipitação média de 650 (MARENGO et al., 2016). Durante essa estação a produção tende a reduzir para 400 mil peças/mês e em épocas de estiagem a produção pode alcançar índices de até 800 mil peças mensais. Essa queda brusca na produção durante o período das chuvas decorre do fato de a indústria enquadra-se como empresa de pequeno porte e utilizar processo de secagem natural, sendo que esse método é altamente afetado pelas mudanças climáticas regionais. 
A perda mensal na produção de blocos verificada na fase de inspeção e carregamento é na ordem de 70 mil peças no período de chuvas. Já nos demais meses do ano essa perda é reduzida para 35 mil peças/mês. $\mathrm{Na}$ fase de secagem em que os blocos ainda se encontram em estado semiacabado, ocorrem perdas por peças defeituosas entre a faixa de 50 a 60 mil blocos mensais. Essas perdas de blocos são devido a umidade do produto ocorrer de forma desproporcional e rápida no período de estiagem. Porém, a perda na etapa de pré-fabricação é caracterizada como geração de rejeitos sendo totalmente reciclado, ou seja, retornam para as etapas iniciais de produção. O mesmo aproveitamento ocorre com as peças defeituosas presentes na saída da máquina extrusora que chega à ordem de $150 \mathrm{mil}$ blocos/mês.

Na etapa de pós-queima são utilizados e descartado mensalmente dez lâmpadas incandescentes de 42 watts para auxiliar na iluminação interna no forno. Na fase de calcinação no forno também é gerado bastantes cinzas (em torno de $1200 \mathrm{~kg} /$ mensais) oriundos da carbonização da lenha usada para o cozimento dos blocos. É importante salientar que essa estimação para quantidade de cinzas foi realizada empiricamente pelo gerente da cerâmica.

A fábrica é composta por 40 funcionários. A empresa não dispõe de refeitório próprio para fornecer a alimentação dos seus colaboradores, assim os mesmos trazem suas refeições já prontas em marmitas de suas próprias residências. A geração de resíduos orgânicos provenientes de sobras de alimentos chega em média de $5 \mathrm{~kg} / \mathrm{semana}$. No empreendimento percebeu-se que os resíduos produzidos na parte administrativa (salas de escritórios), as sobras de alimentos do almoço dos funcionários, EPI's (Equipamentos de Proteção Individual) e demais materiais inorgânicos são depositados dentro de um barril de metal (com capacidade para 200 litros) presente na própria cerâmica e posteriormente são destinados à coleta pública. Em média são descartados na fábrica um total de 200 pares de luvas mensais e 40 pares de botas semestrais.

A indústria em questão utiliza os seguintes equipamentos para realizar o processo de beneficiamento da argila: destorroado, dois misturadores/laminadores, três esteiras e uma Extrusora/maromba. Para realizar a manutenção preventiva de todo esse maquinário a empresa faz a aquisição de graxas e óleos lubrificantes. Durante o ano são utilizados $36 \mathrm{~kg}$ de graxa adquiridos em baldes de 18 quilogramas. Além da graxa, a maromba utiliza 345 litros de óleo lubrificante para funcionar corretamente, sendo necessário efetuar a troca desse óleo depois de um período de um ano. Conforme o gerente da empresa, os baldes de graxas quando esvaziados são doados para os funcionários, o mesmo ocorre com os tambores que armazena o óleo lubrificante. As sobras de óleo que são retirados da máquina extrusora anualmente, também são compartilhadas com os funcionários da cerâmica.

Observou-se também a presença de telhas de amianto quebradas no interior do galpão, configurando-se como nova fonte de resíduo que é integrado à coleta de lixo. Devido às intensas ventanias que ocorrem nas proximidades da empresa em determinadas épocas do ano às telhas de amianto que cobre o galpão são danificadas. Em razão disso os donos estão efetuando gradativamente a troca do telhado de amianto por um telhado de zinco que tem mais resistência e estabilidade.

Na Tabela 1 é apresentado o montante de resíduos sólidos que é gerado pela indústria em questão, bem como a classificação dos mesmos perante a legislação ambiental vigente e a forma de destinação final 
que a empresa vem utilizando para tratar esses materiais. Dentre os diversos resíduos gerados pela fábrica, os que são originados após a etapa de queima (blocos quebrados e as cinzas) são os que apresentam maiores quantidades, sendo classificados como materiais não perigosos e inertes.

Tabela 1: Classificação e composição dos resíduos sólidos.

\begin{tabular}{|c|c|c|c|c|c|}
\hline RESÍDUOS GERADOS & ORIGEM & $\begin{array}{l}\text { QUANTIDADE } \\
\text { PRODUZIDA }\end{array}$ & $\begin{array}{l}\text { CLASSIFICAÇÃO NBR } \\
10.004\end{array}$ & COMPOSIÇÃO & DESTINO \\
\hline Papel/Papelão & Escritório & $6,0 \mathrm{~kg} / \mathrm{mês}$ & Classe II - A & Sólido & Coleta Pública \\
\hline $\begin{array}{l}\text { Embalagens } \\
\text { Plásticas }\end{array}$ & Escritório & 2,0 kg/mês & Classe II - A & Sólido & Coleta Pública \\
\hline Luvas & Etapa de produção & 200 pares/mês & Classe II - A & Sólido & Coleta Pública \\
\hline Botas & Etapa de produção & 40 pares/semestrais & Classe II - A & Sólido & Coleta Pública \\
\hline Blocos quebrados & $\begin{array}{l}\text { Etapa de pós- } \\
\text { queima }\end{array}$ & $\begin{array}{l}168.000 \mathrm{~kg} / \mathrm{mês} \\
\text { (Inverno) } \\
84.000 \mathrm{~kg} / \mathrm{mês} \\
\text { (Estiagem) }\end{array}$ & Classe II - B & Sólido & Entulho no local \\
\hline Cinzas e brasas & $\begin{array}{l}\text { Queima } \\
\text { nos fornos }\end{array}$ & $1.200 \mathrm{~kg} / \mathrm{mês}$ & Classe II - B & Sólido & Entulho no local \\
\hline Óleos & Manutenção & 345 litros/ano & Classe I & Líquido & $\begin{array}{l}\text { Repartição entre } \\
\text { funcionários }\end{array}$ \\
\hline $\begin{array}{l}\text { Lâmpadas } \\
\text { Incandescentes }\end{array}$ & Etapa pós-queima & 10 unidades/mês & Classe I & Sólidos & Coleta Pública \\
\hline Blocos defeituosos & $\begin{array}{l}\text { Etapa de pré- } \\
\text { fabricação }\end{array}$ & $180.000 \mathrm{~kg} / \mathrm{mês}$ & Classe II - B & Sólidos & $\begin{array}{l}\text { Reciclado pela própria } \\
\text { empresa }\end{array}$ \\
\hline Baldes de Graxas & Manutenção & 2 unidades/ano & Classe I & Sólido & $\begin{array}{l}\text { Repartição entre } \\
\text { funcionários }\end{array}$ \\
\hline
\end{tabular}

Legenda: Classe I - Perigoso; Classe II - Não perigoso (A - Não inertes / B - Inertes).

\section{Proposta para o plano de gerenciamento de resíduos sólidos}

De acordo com PNRS, qualquer tipo de atividade industrial está sujeita a elaboração e implementação do Plano de Gerenciamento de Resíduos Sólidos - PGRS. Conforme o Art. 21 desta lei, o PGRS deve conter as seguintes especificações mínimas: a descrição do empreendimento; a avaliação dos insumos gerados contendo a origem, o volume e a caracterização. Além disso, deve estar de acordo com a legislação ambiental existente em plano municipal, estadual e federal; conter a descrição dos procedimentos para tratamento adequado dos resíduos e dispor de ações que possa reduzir ao máximo o descarte de rejeitos no ambiente. O objetivo do Plano de Gerenciamento de Resíduos Sólidos (PGRS) é reduzir a geração de resíduos sólidos, pelo que deve orientar o correto acondicionamento, armazenamento, coleta, transporte, tratamento e destinação final de tais resíduos (DEBASTIANI, 2016).

Apesar de o plano de gerenciamento dos resíduos sólidos ser um elemento obrigatório para setores industriais, conforme citado na lei $12.305 / 2010$, nem toda empresa possui o seu PGRS. Geralmente, na prática esse plano de gerenciamento não é cumprido devido aos elevados custo envolvidos na sua implementação. Durante as visitas realizadas a indústria de cerâmica ficou evidente que o empreendimento não possui nenhum programa ambiental para gerenciar os resíduos sólidos que são produzidos no local.

Os diversos tipos de resíduos que são produzidos na empresa recebem destinação incorreta, sendo acondicionados indevidamente sem qualquer distinção. É importante que todos os resíduos sejam separados de acordo com as suas categorias: papel, plástico, vidros, material celulósico e metais. Segundo a Resolução CONAMA no 275 (BRASIL, 2001) os resíduos oriundos da ação humana devem ser separados em coletores 
plásticos com as seguintes cores padronizadas: a cor azul é atribuída a papel/papelão; a cor vermelha para plásticos; a cor verde para vidro; a cor amarela para metais; a cor laranja para resíduos perigosos; a cor roxa para materiais radioativos; o marrom para resíduos orgânicos e a cor cinza para resíduos não recicláveis. Além do acondicionamento adequado dos insumos, é necessário que a empresa disponha de programas de coleta seletiva e reciclagem dos rejeitos.

Nota-se que a empresa está tendo bastante perda de blocos na última etapa da produção, principalmente no período de chuvas que chega a atingir o dobro da perda na época de estiagem, no total de 168 toneladas de detritos calcinados. Todo esse resíduo está sendo acumulado em uma espécie de entulho nas proximidades da indústria. Segundo Berni et al. (2013) esses detritos quando destinado de forma incorreta pode acarretar vários problemas ambientais, tais como: a contaminação do solo, dos rios e dos lenções freáticos. Para Brasileiro et al. (2015) são várias as possibilidades de reutilização dos resíduos oriundos da quebra de blocos calcinados, sendo que os mais comuns são: a utilização como camadas de base e sub-base para pavimentação, cobertas primárias de vias, fabricação de argamassa de assentamento e revestimento, fabricação de concreto e de produtos pré-moldados.

Segundo Nunes (2012) as indústrias de cerâmica que utilizam secagem natural durante a fabricação de seus produtos devem observar alguns critérios para evitar eventuais perdas no processo, como: trabalhar com umidade de extrusão mais baixa possível; não ultrapassar a altura de cinco peças nas pilhas; colocar os blocos com furos para cima; não deixar formar poças de águas ao lado das leiras; construir leiras em torno de 50 centímetros; distanciar os blocos uns dos outros em pelo menos três milímetros; colocar os blocos nas diagonais invertendo sempre a posição das pilhas e organizar as peças de modo a permitir que o sol ou vendo incidam de forma igual e regular sobre eles.

Outro tipo de resíduo que é gerado no processo pós-queima é a cinza. Foi constatado que o empreendimento não efetua a reciclagem desse resíduo e a mesma é misturada aos blocos cerâmicos que são perdidos nessa etapa. Conforme Marengo et al. (2016) as cinzas oriundas do processo de queima da lenha podem ser utilizadas para adubação do solo favorecendo o cultivo de vegetais. Outra possível destinação é a utilização em argamassas de vedação dos fornos do empreendimento, como forma de reaproveitá-la no próprio processo de produção.

No processo produtivo dessa cerâmica observou-se também o descarte indevido de lâmpadas incandescentes, em vista que esses materiais são considerados resíduos com alto grau de periculosidade. Recomenda-se o armazenamento em bombonas plásticas e destinação a postos públicos e privados para o descarte de todos os tipos de lâmpadas. Assim como as lâmpadas, os baldes de graxa e os recipientes que armazenam os óleos lubrificantes quando totalmente esvaziados são distribuídos aos funcionários da fábrica. Recomenda-se o armazenamento do óleo usado em barril de metal para destinação para empresas de rerrefino.

\section{CONCLUSÕES}

$\mathrm{Na}$ indústria de cerâmica em questão se percebeu a inexistência do plano de gerenciamento dos seus 
resíduos sólidos, estando assim em desacordo com as obrigações ambientais previstas em leis. No empreendimento ficou evidente que o excesso de perda de blocos cerâmicos durante o processo de trabalho, principalmente na etapa de pós-queima, é um dos principais fatores contribuintes para o aumento na produção de materiais que são descartados incorretamente no ambiente. Nesse estágio de cozimento dos blocos também é produzido certa quantidade de cinzas oriundas da queima do combustível sólido, que juntamente com a perda de blocos, é lançado de forma indevida nas proximidades da fábrica.

Outro ponto importante observado, é que a indústria utiliza lâmpadas incandescentes para concluir as atividades desempenhadas nos fornos. Além deste material ser considerado perigoso e está sendo integrada a coleta pública de resíduo comum, a comercialização desse tipo de lâmpadas foi proibida no Brasil desde o ano de 2016. Foi notado também que os responsáveis pela fábrica ao efetuar a manutenção das máquinas e equipamentos, distribui entre os funcionários as sobras de óleo queimado e os recipientes vazios que armazenam essas substâncias. Esse tipo de prática de distribuir material perigoso entre os integrantes da empresa não é considerado um procedimento adequado, pois o empregador não tem controle sobre a forma de destinação final que os seus colaboradores estão atribuindo a esses produtos.

Espera-se que as recomendações impostas nesse estudo sobre o gerenciamento dos resíduos sólidos contribuam para uma gestão ambientalmente correta em relação ao tratamento desses materiais, não só para a indústria em estudo, mas também para as demais de mesmo ramo de atividade. E que os empregadores possam optar por uma produção mais limpa sobre o aspecto ambiental, contribuindo efetivamente em prol do desenvolvimento sustentável.

\section{REFERÊNCIAS}

ABDI. Agência Brasileira de Desenvolvimento Industrial. Estudo técnico setorial da cerâmica vermelha. Brasília: ABDI, 2010.

ABNT. Associação Brasileira de Normas Técnicas. NBR 10.004/2004: Resíduos sólidos: Classificação, Rio de Janeiro: ABNT, 2004.

BERNI, M. D.; BAJAY, S. V.; DORILEO, I. L.. Tecnologias Inovadoras e Eficiência Energética no Segmento de Revestimentos Cerâmicos. Cerâmica Industrial, v.18, n.1, p.29-34, 2013.

BRASIL. Conselho Nacional do Meio Ambiente. Resolução CONAMA n. 275, de 25 de abril de 2001. Brasília: CONAMA, 2001.

BRASIL. Conselho Nacional do Meio Ambiente. CONAMA Resolução n. 307. Brasília: CONAMA, 2002.

BRASIL. Política Nacional de Resíduos Sólidos Lei 12.305. Brasília, 2010

BRASILEIRO, L. L.; MATOS, J. M. E.. Revisão bibliográfica: reutilização de resíduos da construção e demolição na indústria da construção civil. Cerâmica, v.61, n.358, p.178189, 2015.

CARLETI, E. D. S.. Carbono social como meio de correção das externalidades geradas pela indústria cerâmica: caso de sucesso no Cariri Cearense. Dissertação (Mestrado Profissional em Economia) - Universidade Federal do Ceará, Fortaleza, 2013.

DEBASTIANI, S. M.. Proposta de implantação do plano de gerenciamento de resíduos sólidos para uma rede de supermercados, de acordo com as diretrizes da lei $n^{\circ}$ 12.305/2010. Dissertação (Mestrado em Administração), Universidade Estadual do Oeste do Paraná, Cascavel, 2016.

FIEMG, F.; DAS, I. E. M. G.; FEAM, F. E. M. A.. Guia técnico ambiental da indústria de cerâmica vermelha. Belo Horizonte, 2013.

MAIA, F. D. S.. Avaliação de massas cerâmicas, processamento e propriedades dos produtos de cerâmica vermelha do pólo cerâmico de Campos dos Goytacazes. Dissertação (Mestrado Engenharia e Ciências dos Materiais), Universidade Estadual Norte Fluminense Darcy Ribeiro, Campos dos Goytacazes, 2012.

MARENGO, J. A.; CUNHA, A. P.; ALVES, L. M.. A seca de 201215 no semiárido do Nordeste do Brasil no contexto histórico. Revista Climanálise, v. Ediçao Com, n. November, p.49-54, 2016.

MENDONÇA, R. S.. Disposição ambientalmente adequada de resíduos sólidos: efeitos sobre indicadores 
epidemiológicos municipais. Dissertação (Mestrado em Economia) - Universidade Federal de Uberlândia, Uberlândia, 2015.

MORAIS, D. M.. Briquetes de Resíduos Ligno-celulósicos como Potencial Energético para a Queima de Blocos Cerâmicos: Aplicação em uma Indústria de Cerâmica Vermelha que Abastece o Distrito Federal. Tese (Doutorado) - Universidade de Brasília, Brasília, 2007.

MORAIS, M. M.. Gerenciamento de resíduos sólidos na indústria de cerâmica vermelha: um múltiplo estudo de caso na região de desenvolvimento do sertão do São Francisco de Pernambuco. Dissertação (Mestrado Engenharia Ambiental) - Universidade Federal Rural de Pernambuco, Recife, 2015.

MOURA, V. S.. Programa de gerenciamento de resíduos sólidos recicláveis em tupaciguara (mg) - 2007 a 2015.

Dissertação (Mestrado em Geografia) - Universidade Federal de Goiás, Catalão, 2016.

NUNES, M. B.. Impactos ambientais na indústria da cerâmica vermelha. Rio de Janeiro: REDETEC, 2012.

A CBPC - Companhia Brasileira de Produção Científica (CNPJ: 11.221.422/0001-03) detém os direitos materiais desta publicação. Os direitos referem-se à publicação do trabalho em qualquer parte do mundo, incluindo os direitos às renovações, expansões e disseminações da contribuição, bem como outros direitos subsidiários. Todos os trabalhos publicados eletronicamente poderão posteriormente ser publicados em coletâneas impressas sob coordenação da Sustenere Publishing, da Companhia Brasileira de Produção Científica e seus parceiros autorizados. Os (as) autores (as) preservam os direitos autorais, mas não têm permissão para a publicação da contribuição em outro meio, impresso ou digital, em português ou em tradução. 